\title{
English and Reichel share plans for ACRL
}

\section{Vote in the election this spring}

by Ray English and Mary Reichel

$\mathrm{E}$ d note: CERL News offered ACRL candidates for vice-president/president-elect, Ray English and Mary Reichel, this opportunity to share their views with the membership. Although many of the issues facing ACRL are discussed informally at meetings, we want to use this venue to provide a national forum to all members. We hope this will assist you in making an informed choice when you receive your ballot this spring.

\section{RAY ENGLISH}

"Oh, you better start swimming

Or you'll sink like a stone

For the times, they are a-changin'"

$$
\text { -Bob Dylan }
$$

"Toto, I've a feeling we're not in Kansas anymore."

-Dorothy, Wizard of $\mathrm{Oz}$

Writing this position piece has provided a very enjoyable opportunity for me to reflect on the state of academic libraries and ACRL. As I've looked back at the recent past, I'm struck by the extraordinary technological changes in our libraries that have taken place in just the last few years. Ubiquitous computers and networking, Web-based catalogs, library Web pages that provide central access for research, electronic journals, e-prints,

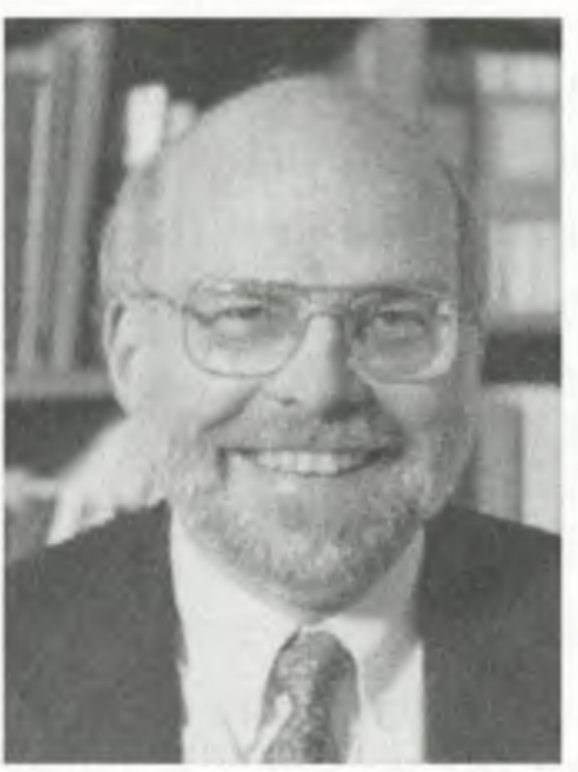

Ray English

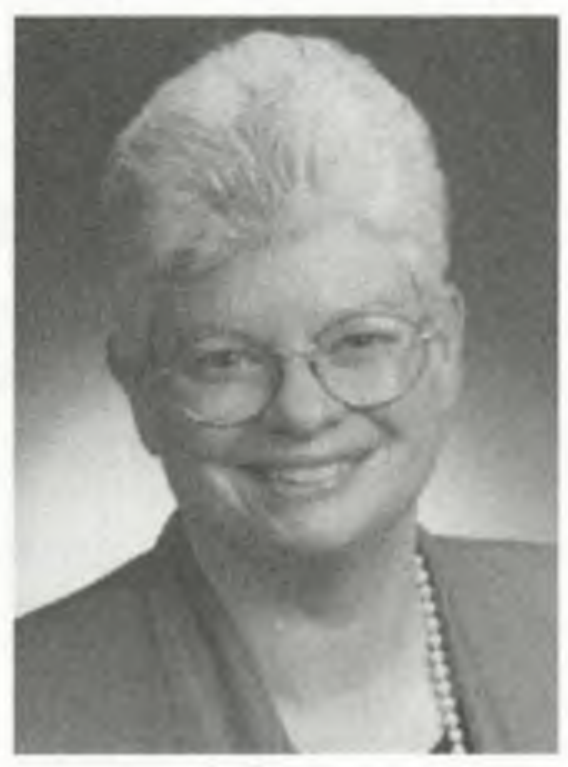

Mary Reichel

e-books, electronic reserves, digital collections (including primary sources of exceptional richness), and distance education are just some of the features of our new landscape.

The new technologies have, in some respects, put us in a position to provide richer information resources for our students and faculty than ever before. But the new environment is also much more complex and demanding, both for our users and for us. As we've provided library resources and services electronically, we've created whole new library functions at the same time that we're continuing the operations of the printbased library.

Staying abreast of such fast-paced change and increasing complexity is essential for all of us. Even more challenging is our need to

\section{About the authors}

Ray English is director of libraries at Oberlin College, e-mail: ray.english@oberlin.edu; Mary Reichel is university librarian at Appalachian State University, e-mail: reichelm/@appstate.edu 
shape the change we're experiencing in accordance with our values, rather than simply let change happen to us.

Only by being leaders, advocates, and activists-both on our own campuses and at state and national levels-can we sustain the quality of our libraries and ensure that they remain central to our institutions' educational missions.

\section{ACRL's response}

ACRL has responded well to the changes in academic libraries, higher education, and our external environment. Our association is very mature, with strong financial resources and a large, stable, active membership. The 1996 strategic plan continued the association's historical emphasis on professional development, but it also placed new priorities on national legislative advocacy and outreach to higher education organizations.

As I write, a new strategic plan is scheduled for adoption by the ACRL Board at the Midwinter 2000 meeting. The new plan will further expand the roles of the association into new areas of critical importance, such as scholarly communication. I fully support the new strategic plan and would work energetically to accomplish its goals. If elected, I would be particularly interested in collaborating with the ACRL Board, committees, sections, and chapters in the following areas.

\section{Professional development}

If we're to deal effectively with the changes transforming our libraries, it's essential that ACRL continues to provide a variety of professional development opportunities. We especially need to build on recent efforts to increase the leadership and advocacy skills of our members.

The association has had great success with its national conferences, annual conference programs, preconferences, and institutes. We need to make these opportunities as accessible as possible to everyone who works in academic libraries. I would place high priority on keeping the costs of conferences and institutes as low as possible and providing scholarship opportunities for those who are not in the best position to participate.

I would also like to encourage further efforts to use technology to make program- ming more available at regional and state levels. The Web broadcast of Jim Neal and Pat Schroeder's debate at the Detroit National conference, which was the focus of the Indiana chapter's state program, is a fine example of what's possible.

\section{Outreach and legislative advocacy}

We face particular challenges at state and national policy levels. Publishing in the digital era is increasingly characterized by licenses and contract law, rather than copyright, and there are continuing pressures from commercial interests to privatize information that has historically been in the public domain. It's now a regular occurrence for us to learn of new bills in Congress that have major implications for libraries. Fair use and wide public access to information can only be assured if we continue to work actively to shape legislation and national information policy.

The recent development of an ACRL legislative agenda, the reallocation of a staff position, and especially the creation of the ACRL legislative network have been very positive responses to these concerns. As a next step, I would encourage ACRL to look for ways to broaden participation by ACRL members in legislative advocacy and to build legislative coalitions with organizations that share our interests. ACRL has been quite successful in creating links to other higher education organizations. It's now time for us to move from outreach to collective action.

\section{Scholarly communication}

It's imperative that we explore all possible avenues to create a scholarly publishing environment characterized by ease of access, fair prices, and archival permanence. The pricing practices of some journal publishers remain a major threat to the quality of all academic libraries.

As prices have gone up faster than budgets, the quality of print collections has declined and the system of scholarly communication itself has come under increasing pressure. In years past, the most problematic publishers have claimed that their price increases were due primarily to increased costs. We now know-beyond any reasonable doubt - that they were motivated by profit maximization and that their prices will 
Even more challenging is our need to shape the change we're experiencing in accordance with our values, rather than simply let change happen to us.

respond to political and competitive pressures.

ACRL's legislative and outreach efforts have put the association in an excellent position to play a much more active role in shaping scholarly communication. As is the case in the legislative arena, we need to work collaboratively with other organizations, especially the Scholarly Publishing and Academic Resources Coalition, to mobilize as much pressure as possible against those publishers who are the worst offenders. We also need to demonstrate through actual examples that high-quality, reasonably priced journals and other forms of scholarly communication are feasible. Finally, we must educate faculty on our campuses about scholarly communication issues. ACRL can play a particularly valuable role in fostering campus education programs.

\section{Information literacy}

Our users face a much more complex information environment than a decade ago. Using that environment to the best advantage requires more skills and abilities. Unless our students become genuinely information literate, rather than simply following an Internet mania, they will increasingly bypass libraries-particularly the printed resources we offer-in favor of what is erroneously perceived to be faster and better means of approaching research problems. In that event, education and academic libraries will both suffer.

We will make real progress in this area only through careful collaboration with teaching faculty on the integration of information literacy into our curricula. The ACRL Institute for Information Literacy, the articulation of information literacy competencies, and the documentation of best practices are wonderful initiatives in this area. They deserve ACRL's continuing strong support, as do ACRL President-elect Betsy Wilson's plans to develop broader collaboration among different types of libraries and other organizations interested in this issue.

\section{Composition of the profession}

ACRL's most recent survey of membership indicates that we are mostly middle-aged or older, and that we're overwhelmingly Caucasian. Students, our primary user group, are becoming increasingly diverse. In addition, academic libraries are experiencing problems in filling vacant positions. We must strengthen recent efforts to recruit new librarians into academic libraries and also redouble our efforts to diversify the profession. ALA's Spectrum Initiative, the recent Congress on Professional Education, and ACRL's discussions with library school deans offer good beginning points for our work in this area.

I believe that one of the keys to our success involves encouraging all academic libraries to begin programs to recruit students-especially those from underrepresented groups-into the profession. Virtually all of us employ significant numbers of student workers and many of use have quite diverse student bodies. As an initial effort we can all initiate programs designed to diversify our student work forces and to demonstrate to students the exciting possibilities of library careers. I would be particularly interested in developing models for academic libraries in these areas. It's also essential that we continue dialogue with library schools to ensure that their curricula are as responsive as possible to the needs of academic libraries.

\section{Conclusion}

Given all the issues and challenges we face, it's natural to wonder if it's even possible to shape the direction of change. It's also natural to wish for a simpler time and place. (Can't we somehow click a pair of red shoes and return to Dorothy's Kansas?) But we all know there is no going back-and no standing still. The times require more and more that we be activists in virtually all aspects of our professional lives. If we don't want to sink like Dylan's metaphorical stone, we all have to swim.

I want to thank the Nominations Committee for selecting me as one of two candi- 
dates for ACRL President for the year 200102. Having recently served on the ACRL Board, the ACRL Executive Committee, and as chair of the ACRL Budget and Finance Committee, I feel that I am very familiar with the issues that confront our association and well qualified to serve in this capacity. I would enjoy the challenge of bringing an increased sense of activism and engagement to our association.

\section{MARY REICHEL}

It is an honor to be asked to run for President of ACRL and I would like to start my statement by sharing with the readers the strengths I believe I would bring to the role.

I have been an academic librarian since 1974 (over a quarter of a century, but who is counting?) and an active member of ACRL and ALA since 1977. Through the years I have been active in ACRL as chair of the Instruction Section, chair of Appointments and Nominations Committee, chair of the President's Program Planning Committee, and a member of the ACRL Board. I have devoted the time, energy, and resources to these endeavors because ACRL is important for each of us as individuals and for all of us as a profession.

I have gained far more than I have given to ACRL by coming to know librarians from all over the country, from different types of higher education institutions, from different backgrounds, and with different priorities.

There is no doubt in my mind that I am a far better librarian because of my involvement in ACRL and ALA, and I would like to see ACRL continue to provide activities and forums that help individuals develop into the best academic librarians and staff they can become. Sharing ideas, research, problems, and solutions is a powerful means of improving ourselves and academic library services.

ACRL's importance for our profession and for academic libraries cannot be overstated. While part of ALA and its overall concerns, ACRL is the professional voice for the academic library community in all types of higher education institutions. I am proud of the increasingly proactive stance that ACRL is taking in publicizing its standing as the organization representing all academic libraries and librarians. I agreed to be nominated for the president's role, in part, because I believe I can provide leadership that will help the association become even stronger.

\section{Strengths}

My individual strengths include the ability to keep my eye on the ultimate goal, the big picture of what we are striving to achieve. Understanding the overview allows a focus on what is truly important and the ability to cut through red tape when necessary to get something done. I am respectful of the association's operating principles, but I also know that expeditious guidance through the bureaucracy will make the association much more meaningful to individuals who want to see change or who want to complete a goal.

Another of my strengths is my ability to listen to others and to pull people together for more powerful decisions through consensus than would have been reached individually. I understand how the Board works, how the ACRL staff interacts with the Board, how ACRL relates to ALA, and I would work to make the Board as accessible to members as possible. At the same time, members need the Board to be serious about its ficluciary responsibilities. My service on the SOLINET Board, as well as the ACRL Board, has led to a strong understanding of the financial aspects of organizations.

\section{Priorities}

As president, I would support ACRL's strategic plan and I would emphasize 1) recruitment to our profession and broadening member participation in the association; 2) ACRL's strong legislative and policy focus; and 3) closer connections with other higher education groups through an emphasis on the importance of information literacy and scholarly communication.

As we expand recruitment of bright, talented individuals from a variety of aca- 
I would like to see ACRL continue

to provide activities and forums

that help individuals develop into

the best academic librarians and staff they can become.

demic disciplines, I believe academic librarianship and ACRL will thrive only if we are successful in increasing ethnic diversity among our colleagues and in ACRL. To that end, I would try to make appointments within the association that would increase diversity among active members. I would support the work of the Ad Hoc Committee on Recruiting into the Profession, implement its recommendations, and examine the need to make recruiting a standing committee, as well as supporting such efforts as Job Shadow Day.

As a Board member, I watched (and I hope helped) ACRL strengthen our involvement in legislative and policy issues. Devoting staff time to legislative and policy activities made timely notice of emerging issues possible and allowed a broader representation of academic librarians to respond to these important issues. The renewed dedication to helping shape legislation and policy also reinvigorated the Government Relations Committee. This initiative has improved our relationship with the Association of Research Libraries. I would do what is necessary to continue this emphasis.

\section{Information literacy and scholarly communication}

The cornerstone of my career and my participation in ACRL has been my belief in the importance of what we do as academic librarians, especially our involvement with the education of undergraduate and graduate students. In these wonderful, exciting, and challenging times, information literacy is more essential than ever for students.

Students prefer easily accessible resources; research shows that librarians/researchers/ faculty members also prefer easily accessible resources. It is no surprise then that the Internet is so popular. We have the challenge and excitement of helping students learn the necessary critical thinking and evaluation abilities to determine whether the easily accessible resources are also the most suitable resources for the academic task or project. Being in academic libraries now allows us the luxury of focusing on students' evaluation of resources and use of them.

Similarly, academic libraries' role in the scholarly communication process is a vital one. Librarians reach faculty, administrators, and staff through not only our support of the research process, but also in our leadership in helping researchers understand the full dimensions of the scholarly communication process.

Faculty respect for libraries and their interest in collaborating with librarians in the educational process is derived from the support they receive in accomplishing their own research and in understanding the "food chain" of scholarly communication-from researcher to publisher to libraries and back. In our own right, ACRL has a distinguished history of promoting research related to academic libraries and information studies.

As president, I would continue to support College and Research Libraries and our other publications that advance knowledge in our field. In fact, we are a model of a successful nonprofit, scholarly publishing effort.

As President of ACRL, I would tie my selected priorities to current initiatives, such as the Institute for Information Literacy and a continual emphasis on the bright future of academic libraries, and the role libraries play in the educational and scholarly communication process. With this emphasis, a closer relationship to higher education is a natural priority.

Strong academic libraries are key to a strong higher education for undergraduate and graduate students. That future may come in a different set of clothes from the ones we have been wearing, but the necessity for strong libraries continues.

Explaining the importance of academic libraries is a crucial role for ACRL, and, as President, I would ask the association to define what we think academic libraries, services, and collections will be in 2010 and beyond. We can develop a model vision that will be useful for us as a profession and on our campuses as a guide to the future of academic libraries. 
Offering degrees in stimulating fields. Presented through three week summer residency and on-line classes.

\section{Interested in Advanced Study at the Ph.D. or M.A. level?}

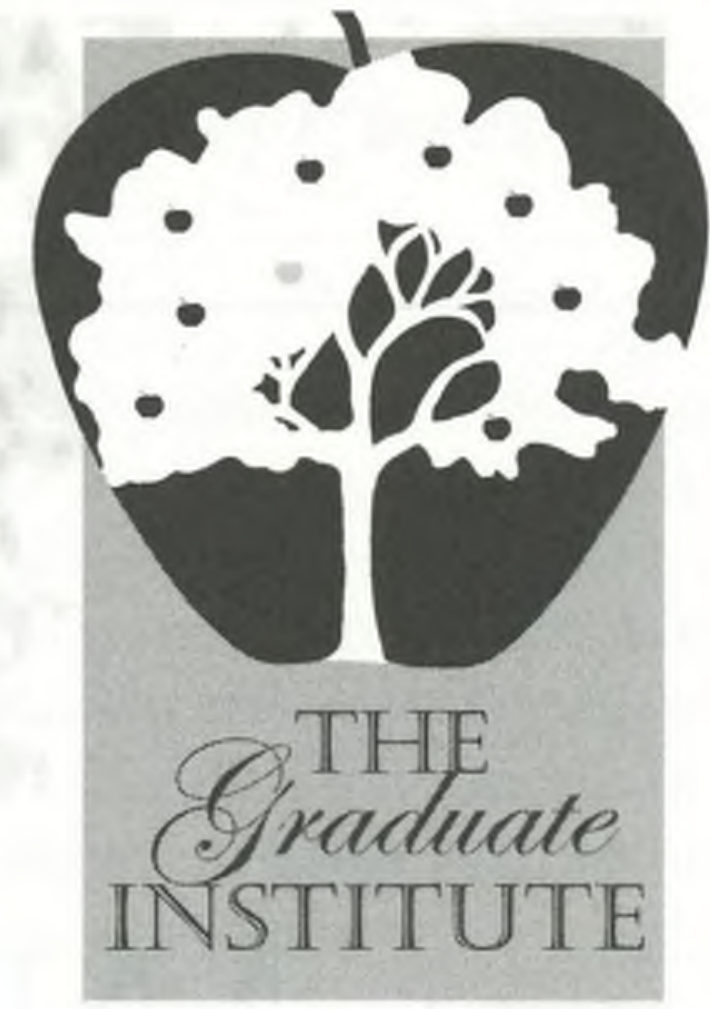

The Graduate Institute offers the only Master of Arts in Oral Tradition. It also provides the gateway to the research-only Doctor of Philosophy from Lancaster University in England. Consider the opportunity for advancement through three weeks of on-site study and continuous on-line independent learning.

... dynamic and unique programs for life long learners in their search for values and meaning.
- Poignant learning, critical in the library sciences

- The convenience of self-directed inquiry

- High quality instruction and valuable degrees
- Engaging and productive cohort design

- Practical experiences for career development

- Exciting learning events

\section{ONaclor of Philosophy in RESEARCH}

A research only (no taught classes!) experience guided by extraordinary supervisors and mentors. And it's affordable!

\section{Master of Oyres in ORAL TRADITION}

Explore the practices and performances in many cultures, mythologies and folktales. Featuring extraordinary storytellers, mentorship, children's literature, and studies of spiritual and religious oral traditions. Development of school curriculum to promote verbal skills through storytelling, and investigation of therapeutic applications.

\section{Master of Orris in CONSCIOUS EVOLUTION}

Focused on evolutionary societal changes and the dynamic forces of human spirit and awareness.

$$
\text { Master of OSres in HOLISTIC THINKING }
$$

Creative thinking processes and the integration of academic disciplines into systematic worldviews.

\section{Master of ONres in EXPERIENTIAL HEALTH \& HEALING}

Effects and meaning of patient - healer interactions, and the integration of allopathic and complementary approaches to humanistic medicine.

\section{Frax mare information..}

or an application, please contact:

The Graduate Institute

701 North Street

Milford, Connecticut 06460

Or call: (203) 874-4252; fax (203) 874-8070

email:gradinst@connix.com
The Graduate Institute is a division of The Leaning Collaborative Inc., a non-profit educational organization dedicated to the evolution of learning and new teaching environments, is an equal opportunity organization. 


\section{ANY JOURNAL}

\section{ANY FORMAT}

\section{ANY TIME}
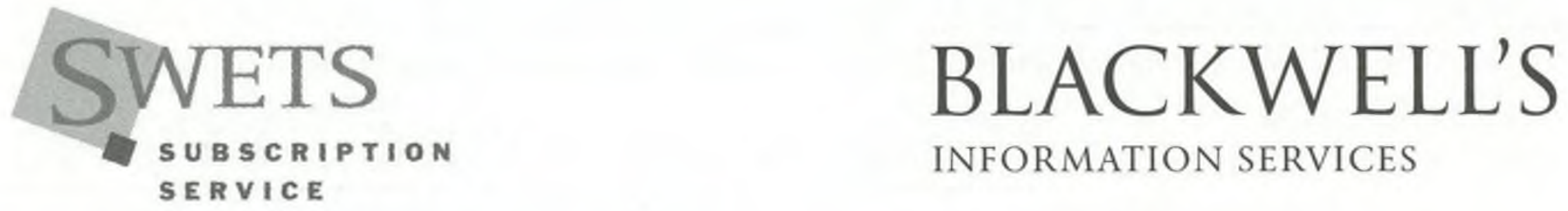

INFORMATION SERVICES

Continuing our tradition of excellent service to libraries worldwide.

Swets \& Zeitlinger, Inc

440 Creamery Way, Suite A

Exton, PA 19341-2551

Phone: 800-447-9387

Fax: $800-590-9850$

Email: info@swetsinc.com

http://www.swetsinc.com
New Jersey Service Center

PO Box 1257

Blackwood, NJ 08012

Phone: 800-458-3706

Fax: 856-232-7934

http://www. blackwell.co.uk
Oxford Service Center

PO Box 40, Hythe Bridge Street

Oxford OX1 2EU, UK

Phone: 011441865792792

Fax: 011441865262538

http://www.blackwell.co.uk 